\title{
Emerging Nutraceutical Companies in India- A Link between Food and Medicine
}

\author{
Kajal Saini ${ }^{1}$ and Keshav Saini ${ }^{2}$
}

1. Department of Environmental Sciences, J.C. Bose University of Science and Technology, Faridabad, Haryana

2. Department of Food Technology, Jaipur National University, Jaipur, Rajasthan

\begin{abstract}
Nutraceuticals are combination of nutrients and pharmaceuticals and these are derived from various plants, microbes and animals too. The food products that are considered as nutraceuticals are categorised based on the availability in the market. It is a medical approach to improve health and remedy for illness. Nowadays there is an increase in shift towards use of nutraceuticals as its usage provides preventive therapies to various chronic diseases. Various natural nutraceuticals are based on extracts from Ginger, turmeric, garlic, amla, cinnamon, aloe vera etc. A wide variety of therapeutic values are provided by them such as anti-inflammatory, antibacterial, antifungal properties, allergy relief, antidiabetic and cardiovascular problems. India is in its infancy stage but have many emerging companies that are trying to meet the demand of growing population. Overall 'Nutraceuticals' has been known as a new era of well being, in which the food industry has become a main player.
\end{abstract}

Keywords- Nutraceuticals, pharmaceuticals, medical approach, therapeutic, therapies, emerging companies.

\section{Introduction}

Nutraceuticals comprises of "Nutrient" + "Pharmaceuticals" as they possess nutritional along with medicinal values [1]. In 1989, Dr. Stephen De Felice coined the term "Nutraceuticals". It is generally defined as a substance which provides physiological benefits and mainly focuses on prevention and less on treatment of diseases especially chronic diseases $[2,3]$. Nutraceuticals are derived from various food products like garlic, peanuts, aloe vera and cinnamon and other plants, microbes and animals also. Apart from basic nutrients that obtain from food it provides additional nutrition. It may use to improve health and well being, increase life expectancy, weight management, mitigate gastro intestinal problems and so on [4,5]. Nutraceuticals in various countries are still in its infancy stage including India [6], which is the second most populated country after China. The growing population creates problems related to distribution of health, wealth and other services. Nutraceuticals are the favourable solution to combat nutritional and health related problems. There are various small companies of Nutraceuticals in India but play a very big role to combat the health related problems. 


\section{Concept of Nutraceuticals [7]}

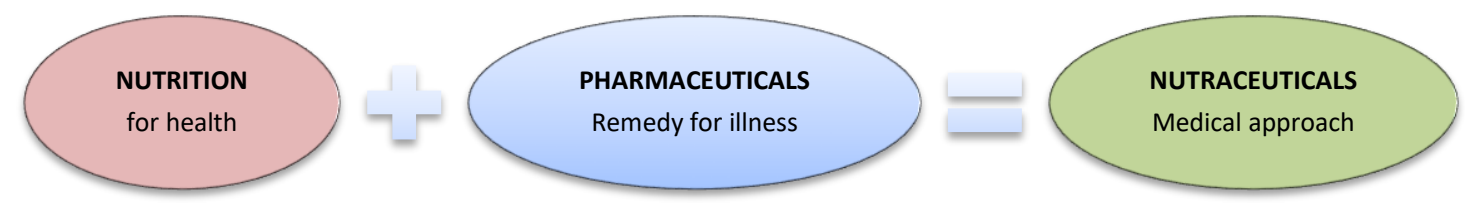

Nutraceuticals mainly comprises of:

1. Phytochemicals (botanical origin)

2. Nutrients (minerals, fatty acids, vitamins)

3. Dietary supplements (prebiotics, probiotics, enzymes)

\section{Need to Shift towards nutraceuticals [8-10]}

- Many people are becoming health conscious with time

- Food is being processed so much that some of its nutrient are lost

- People are losing faith in pharmaceuticals to prevent chronic diseases

- The world's population is growing very fast

- These are economically affordable

\section{Classification of Nutraceuticals [11,12]}

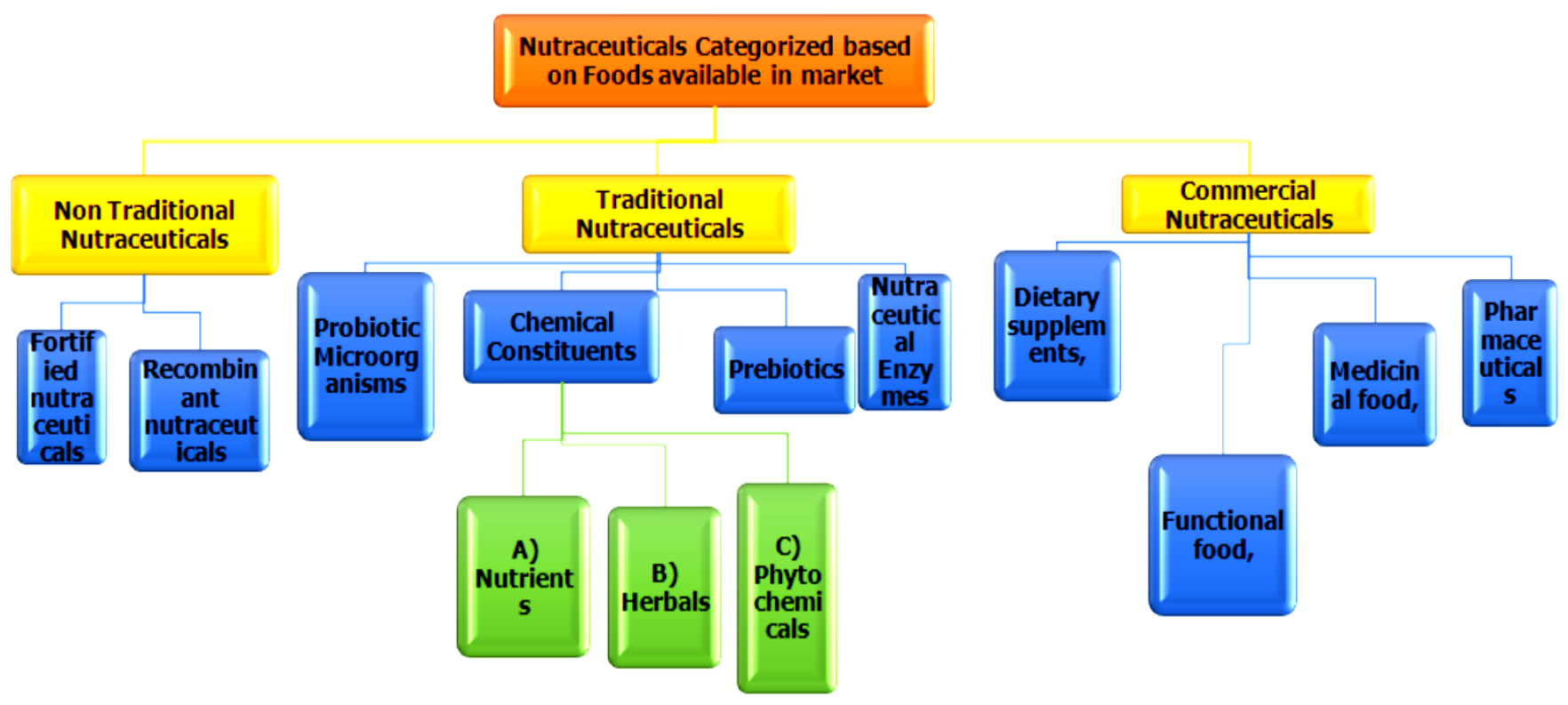


Table: Natural Nutraceuticals with their Therapeutic benefits [13-24]

\begin{tabular}{|c|c|}
\hline Nutraceuticals & Therapeutic benefits \\
\hline Garlic & $\begin{array}{l}\text { Diabetic support, lower cholesterol, cardiac diseases, } \\
\text { weight loss, aids in digestion, hypotensive anti } \\
\text { inflammatory, antifungal, antibacterial ,antithrombotic }\end{array}$ \\
\hline Ginkgo biloba & Allergy relief \\
\hline Cinnamon & Control diabetes, prevent cancer \\
\hline Ginger & $\begin{array}{l}\text { Positive inotropic, antiemetic, carminative. Help in } \\
\text { digestion, antioxidant, treatment of liverfibrosis }\end{array}$ \\
\hline Aloe vera & $\begin{array}{l}\text { Weight loss, immunity booster, anti inflammatory, wound } \\
\text { healing }\end{array}$ \\
\hline Ajwain & Prevents regurgitation, prevents cardio vascular diseases \\
\hline Clover, Oats, Lucerne, Carrots & Neutralize free radicals \\
\hline Green tea & Antibacterial activity, lowering cholesterol, \\
\hline Tomatoes & Antioxidant \\
\hline Citrus fruits & $\begin{array}{l}\text { Antioxidant, lower blood homocysteine, endothelial } \\
\text { function }\end{array}$ \\
\hline Grapes & $\begin{array}{l}\text { Antioxidant, platelets aggregation, anti inflammatory } \\
\text { action }\end{array}$ \\
\hline Legumes & Anti inflammatory functions \\
\hline Bell pepper & Antioxidant, prevent blood clot in heart attack problems \\
\hline Turmeric & $\begin{array}{l}\text { Help in inflammation, digestion, antioxidant, antibacterial } \\
\text { property, treats multiple chronic diseases }\end{array}$ \\
\hline Amla & Anti aging, diabetes, diuretic, osteoarthritis \\
\hline Ground apple & $\begin{array}{l}\text { Indigestion, insomnia, menstrual disorders, haemorrhoids, } \\
\text { wound healing, fever, muscle spasms, rheumatic pain }\end{array}$ \\
\hline
\end{tabular}




\section{Emerging Nutraceuticals companies in India}

There are many large well known nutraceuticals producing companies in India like Dabur India Limited, Reliance Wellness Limited, Amway India Enterprises Pvt. Limited, The Himalayan Drug Company, Piramal Healthcare limited etc but there are also some small emerging players in nutraceuticals which contribute in the wellness of the nation, some of these are as:

\section{GC Rieber Compact India Private Limited}

GC Rieber is an emerging company that works for human wellness and food for life. In 1948, GC Compact AS was established in Norway. In 2009 Compact AS established GC Rieber Compact in Gurugram, Haryana, India. This company produces ready to use products generally lipid based nutrient supplements derived from peanuts as it is good source of lipids and help to mitigate malnutrition. It is certified with FSSC-22000.

Categories of products manufactured by GC Rieber:

1. Products for maritime survival

2. Products for preparedness and emergency (BP- 5 and BP-ER)

3. Products for malnutrition (Supplementary products that are based on lipids- eeZee 20, eeZee 50, eeZee RUTF, eeZee RUSF) [25]
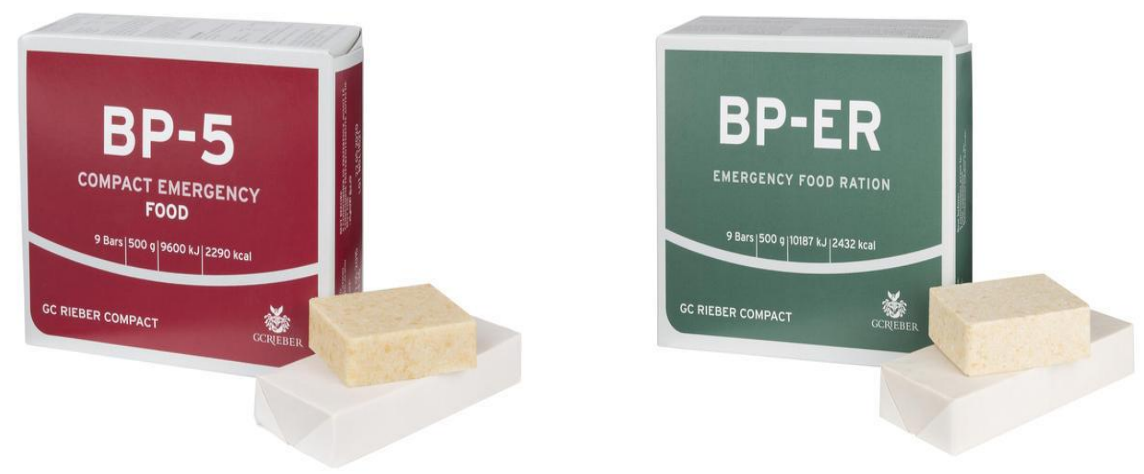

Figure: BP-5 and BP-ER

\section{Nutraculture India Limited}

Nutraculture India Limited was established in Chandigarh in 2012 with the aim to provide natural solution for problems of today's diverse population and aspires to fulfil the requirements.

Products manufactured by Nutraculture India Limited: 
- NutraCulture $^{\mathrm{TM}}$ Phycocyanin ${ }^{\mathrm{TM}}$ (natural dietary supplement dedicated to fight and prevent cancer)

- NutraCulture ${ }^{\mathrm{TM}}$ Englina $^{\mathrm{TM}}$ (dietary supplement made with phycocyanin enriched with spirulina in addition with amla extract, dedicated to provide nutrition, stamina and energy).

- NutraCulture ${ }^{\mathrm{TM}}$ Spirulina (increase absorption of nutrients and provide immunity against infections).[26]

\section{Greenfield Naturals Private Limited}

It was established in 2009 in Dehradun, Uttarakhand. It is one of the top manufacturer and supplier of plant extract, botanical and herbal products in India.

Some of the products that are manufactured by Greenfield Private Limited:

- Garcinia cambogia extract- It is used for weight loss. It inhibits the synthesis of cholesterol, triglycerides and fat. Also consider as an antiulcerogenic agent.

- Momordica charantia extract- Also known as an extract of bitter gourd. It is very useful in liver diseases, gout, spleen diseases and rheumatism. It is also very effective in purifying blood.

- Green coffee bean extract- Extracted from green beans of plant coffee arabica. It contains chlorogenic acid, antioxidants and low in caffeine.

- Curcumin Extract powder- It is an extract of Curcuma longa which is the source of turmeric. It is having many medicinal properties. It blocks cancer causing agents, helpful in maintaining cholesterol level and obesity. It is also acts as an anti-inflammatory agent.

- Tribulus Terrestris Extract- It is a herb belong to zygophyllaceae plant family found in tropical regions of the world. It is urinary antiseptic and non irritant used to treat headaches, nervousness, high blood pressure, rib pain, eye problems and urinary stone. [27]

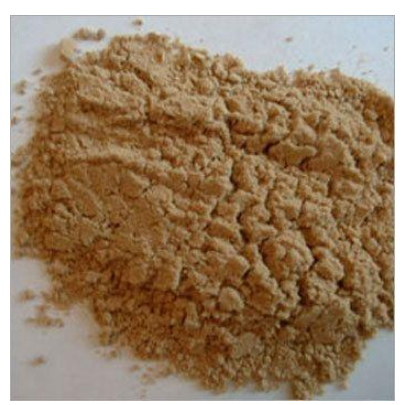

Figure: Tribulus Terrestris Extract

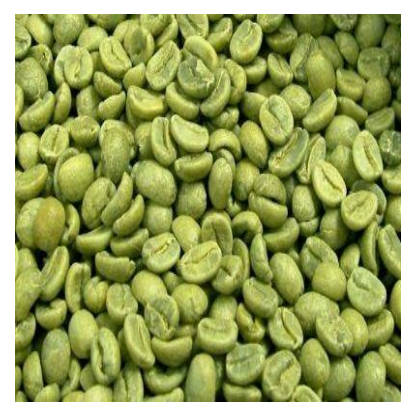

Figure: Green Coffee Bean Extract

\section{Some other Companies are listed here as:}


- Sano Cito Therapeutic Inc

- Neocare Naturals Limited

- Salius Pharma Private Limited

- Pragati Biocare Private Limited

- Herbo Nutra

- Vitromed Healthcare

- Elmed Lifesiences Private Limited

- Xena Bioherbals Private Limited

- Sigma Aldrich

- Novozymes

- Sanofi Genzyme

- Hester

\section{Conclusion:}

Botanical products have been known for their medicinal values for many centuries as mentioned in the Ramayana and the Mahabharata. In this modern era also these are considered to be more valuable than drugs that are obtained from aquatic and terrestrial animals. Nutraceuticals are consider as better option to prevent chronic diseases rather than treatment of diseases as all know Prevention is better than cure. This reflects the merits of nutraceuticals over drugs. Indian Companies have entered in the field of nutraceuticals production and supplier in India and all across the globe. There are many emerging companies that have proven that nutraceuticals can meet the need and wellbeing of the growing population without compromise with the nutrition. Overall, it can be seen that nutraceuticals will proved to be a boon for humans.

\section{References:}

1. Raj KK. Nutraceutical and Functional Food as Future Food: A Review, Scholars Research Library 2 (1); 2010: 106-116.

2. Nasri H, Baradaran A, Shirzad H, Rafieian-Kopaei M. New Concepts in Nutraceuticals as Alternative for Pharmaceuticals. Int J Prev Med 2014;5:1487-99

3. Rajasekaran A, Sivagnanam G, Xavier R. Nutraceuticals as therapeutic agents: A Review. Research J. Pharm. and Tech. 1(4); 2008: 328-340.

4. Chaudhari SP, Powar PV and Pratapwar MN. Nutraceuticals: A Review. World J Pharm Pharm Sci. 6(8);2017: 681-739.

5. Srivastava RK. Need Of Nutraceuticals / Functional Food Products for Health Benefits to World-Wide People. J. Biomed Biotechnol 1(4); 2018: 1-13. 
6. Chauhan B, Kumar G, Kalam N, Ansari SH. Current concepts and prospects of herbal nutraceutical: A review. J Adv Pharm Tech Res 2013;4:4-8.

7. Consumer Association of Canada. Available from: http://www.consumermanitoba.ca / resources.html. Accessed on date March 8,2009

8. John Maxwell. Denis Smith, Mike Brewster, Susan Eggleton, Food as pharma as wellness products evolve, the distinction between food and medicine blurs. R\&C worlds express, 2012. http://www. pwc. com/gx/en/retail-consumer/pdf/rc-worldsnewsletter-foods-final. Pdf.

9. Olaiya C. O, Soetan K. O, Esan A. The role of nutraceuticals, functional foods and value added food products in the prevention and treatment of chronic diseases M. 1, African Journal of Food Science, 2016; 10(10): 185-193.

10. Prevesh Kumar, Nirdesh Kumar and Tushar Omer, Nutraceuticals- critical supplement for building a healthy India, World Journal Of Pharmacy And Pharmaceutical Sciences, 2016; 5(3): 579-594.

11. Kharb S, Singh V. Nutriceuticals in health and disease prevention. Indian J. Clin. Biochem, 2004; 19(1): 50-53.

12. Shinde N, Bangar B, Deshmukh S, Kumbhar P. Nutraceuticals: A Review on current status. Research J. Pharm. and Tech, 2014; 7(1): 110-113.

13. Patil CS. Current trends and future prospective of nutraceuticals in health promotion, BIOINFO Pharmaceutical Biotechnology 1(1); 2011: 01-07.

14. Sarin R, Sharma M, Singh R, Kumar S. Nutraceuticals; Review,International Research Journal Pharmacy, 3 (4); 2012: 95-99.

15. D. Padmavathi. A general review on "Nutraceuticals": Its golden health impact over human community, 3(2);2018:214-217

16. Tyler VE and Foster F. Herbs and photochemical, In: Covington TR, Berardi RR, Young LL et al. editors. Handbook of Non prescription Drugs. Washington DC: AmericanPharmaceutical Association; 1996.

17. J. Perez-Jimenez and F. Saura-Calixto, "Grape products and cardiovascular disease risk factors," Nutrition ResearchReviews, vol. 21, no. 2, pp. 158-173, 2008.

18. R. Aguirre and J.M.May, "Inflammation in the vascular bed: importance of vitamin C," Pharmacology and Therapeutics, vol. 119, no. 1, pp. 96-103, 2008.

19. P. J. Mink, C. G. Scrafford, L. M. Barraj et al., "Flavonoid intake and cardiovascular disease mortality: a prospective study in postmenopausal women," American Journal of Clinical Nutrition, vol. 85, no. 3, pp. 895-909, 2007.

20. Pandey N, Prasad MR, Rai SK, Rai SP, Medicinal plants derived nutraceuticals: A re-emerging health aid. Int J Pharm Bio Sci, 2,2011: 420-41.

21. Srividya AR, Venkatesh N, Vishnuvarthan VJ, Nutraceutical as medicine. Int J Asia Pac Sci, 1, 2010;132-45.

22. Sumantran VN, Kulkarni A, Chandwaskar R, Harsulkar A, Patwardhan B, et al. Chondroprotective Potential of Fruit Extracts of Phyllanthus emblica in Osteoarthritis. Evid Based Complement Alternat Med, 5(3),2008; 329-35.

23. Kunnumakkara AB, Bordoloi D, Padmavathi G, Monisha J, Roy NK, et al. Curcumin, the golden nutraceutical: multitargeting for multiple chronic diseases. Br J Pharmacol. Jun,174(11), 2017; 1325-1348. 
24. Chauhan ES, Jaya A, (2017) Chamomile an Ancient Aromatic Plant - A Review. J Ayu Med Sci, (4), 251-5.

25. https://www.gcrieber-compact.com/locations/india

26. https://www.google.com/search?rlz=1C1CHBF_enIN751IN751\&ei=4Fn3XqraI5rRr QHUk7SYDA\&q=nutraculture+india+limited\&oq=nutraculture+india

27. https://www.naturaltherapyindia.com/greenfield-naturals 